\title{
Where Is It? Examining Post-Secondary Students' Accessibility to Policies and Resources on Sexual Violence
}

Jacey Magnussen

University of Calgary

Irene Shankar*

Mount Royal University

\begin{abstract}
Faced with a growing demand for adequate policies and programs that meaningfully address sexual violence on campus, the provinces of British Columbia, Ontario and Manitoba have introduced legislation requiring all post-secondary institutions to institute a sexual assault policy. The remaining provinces and territories do not have similar legislation. In absence of such legislation, using the case study of Alberta, we examined how equipped post-secondary institutions in this province are to assist students in need. Utilizing publicly available data we examined: 1) whether Alberta's post-secondary institutions have a sexual violence policy which is readily and easily accessible to the student; and 2) the ease with which students can access university resources and support services for sexual violence. The results indicate that most institutions do not have an accessible policy and support services for students in need. We are hopeful that this study can inform those designing and advocating for sexual violence policies on campus to institute measures to clarify institutions' sexual violence policies, increase accessibility to those policies, create policies where they are missing, and work on clarifying the availability of resources for students on and off campus.
\end{abstract}

This manuscript is the result of co-authorship and author names are listed in alphabetical order. 


\section{Résumé}

En réponse à la demande croissante de politiques et de programmes adéquats pour lutter directement contre la violence à caractère sexuel sur les campus, les provinces de la Colombie-Britannique, de l'Ontario et du Manitoba ont élaboré des lois qui exigent que tous les établissements postsecondaires établissent une politique en matière d'agression sexuelle. Les autres provinces et territoires n'ont aucune loi en ce sens. À partir du cas de l'Alberta, qui ne possède aucune loi en la matière, nous avons étudié dans quelle mesure les établissements postsecondaires de cette province étaient outillés pour aider les étudiants et étudiantes qui en ont besoin. À l'aide de données publiques, nous avons examiné 1) si les établissements postsecondaires albertains étaient dotés d'une politique en matière de violence à caractère sexuel qui soit facilement accessible à la communauté étudiante et 2) dans quelle mesure la communauté étudiante pouvait accéder facilement aux ressources et aux services de soutien offerts par l'université aux victimes de violence à caractère sexuel. Cet exercice nous a permis de constater que la plupart des établissements n'ont pas de politique ou de services de soutien accessibles aux étudiants dans le besoin. Nous espérons que cette étude pourra profiter aux acteurs responsables des politiques relatives à la violence à caractère sexuel sur les campus et aux acteurs militant en ce sens, afin qu'ils puissent instaurer des mesures visant à clarifier ces politiques, à élargir leur accessibilité, à créer de telles politiques là où elles sont inexistantes et à améliorer l'accès aux ressources mises à la disposition de la communauté étudiante, tant sur le campus qu'à l'extérieur de celui-ci.

\section{Introduction}

The news is saturated with stories documenting universities' failure to adequately help students victimized by sexual violence. For instance, in 2014, 23 students from Barnard University ${ }^{1}$ filed a federal complaint against their school for their derisory response to sexual assault complaints (Browne, 2014). Ms. Emma Sulkowicz was among these 23 students who filed the federal complaint. Ms. Sulkowicz made international headlines for her senior thesis project titled "Carry That Weight" (Altier, 2015) in an effort to bring attention to her sexual assault by a fellow student in 2012. Ms. Sulkowicz decided to bring public attention to the issue of sexual violence on campus upon finding out that her assailant had also assaulted two other students (Browne, 2014). She protested her university's complicity, through their refusal to expel her rapist, by carrying her mattress everywhere she went on campus (Altier, 2015).

Canadian universities also appear ill-equipped to deal with sexual violence (Quinlan et al., 2016). For example, at the Université du Québec à Montréal a study found that 3,400 (or $36.9 \%$ of their participants) had been sexually assaulted by someone linked to their university, with $42 \%$ of those being victimized more than once (Enos, 2017). Despite such high numbers, university policies and services continue to be patchwork at best. For instance, in the 2014/15 academic year, the University of Toronto reported zero suspen- 
sions, expulsions or disciplinary consequences despite the 137 informal complaints of sexual assault (Desai, 2016). Students who came forward with allegations of sexual assault at the University of Toronto were forced to sign confidentiality agreements and encouraged to stay quiet about the incidents (Desai, 2016). Similarly, in early 2016 it came to public attention that Brandon University required victims of sexual violence to sign a confidentiality contract that required them to only speak of their sexual assault to school counsellors. If they disclosed their assault to anyone besides the school counsellors they could be suspended or expelled from the university ${ }^{2}$ (Laychuk, 2016). More recently, in January of 2018, University of Calgary reported that it lacked grounds to expel Connor Neurauter, a 21-year-old student who had plead guilty to sexual interference of a 13-yearold child, because the assault had taken place prior to Neurauter's enrollment at U of C (Pike, 2018). University of Calgary made this public statement in response to the public outrage over the sentencing concessions, which would have allowed Neurauter to delay his 90 days prison sentence in order to complete his classes. Part of the outrage stemmed from the inadequacy of University of Calgary policies, which do not require expulsion of students convicted of sexual offences.

There is a persistent failure in post-secondary institutions' sexual violence policies (where available), which hinders the ability of these institutions to provide timely assistance and information to students in need. As indicated in a recent York University study, while $88 \%$ of students reported receiving information on sexual assault, $78 \%$ of respondents did not know how to obtain further information in order to report sexual violence on campus (Gray \& Pin, 2016). Overall, this study shows that: a) students lack information on reporting sexual violence and what to expect after they report their assault, b) racialized students were significantly less likely to be aware of the sexual assault resources on campus, and c) more female-identified students reported feeling unsafe on campus regardless of the time of the day than their male counterparts (Gray \& Pin, 2016).

There is a pressing need for meaningful policies and resources on sexual violence that are responsive to the realities of sexual violence and readily accessible to students in need. Accordingly, using publicly available data, we examined the availability and accessibility of sexual violence policies and support programs at Alberta's post-secondary institutions.

\section{Literature Review}

\section{Sexual Violence}

Propelled by public disclosure of the lengthy history of sexual violence committed by Hollywood power players such as Harvey Weinstein and Kevin Spacey, along with the \#metoo and Times Up movements, women are publicly speaking about their experiences of sexual violence. There is a growing acknowledgement of the myriad ways in which women are subjected to sexual violence in their daily lives.

Among Canadian women, the self-reported rates for sexual violence are 37 per 100 (Conroy \& Cotter, 2017). Sexual violence is a gendered social problem, with women most often being the victims, and men most often perpetrating sexual violence (Benoit et al., 2015). Moreover, an intersectional approach to sexual violence is key as not all women are equally likely to be victimized (Benoit et al., 2015). Indigenous, 2SLGBTQIA, people with 
disabilities, minorities, and international students are at higher risk of sexual violence (Benoit et al., 2015; Enos, 2017; Day, 1994; Gunraj et al., 2014). For instance, sexual assault is three times higher for Indigenous people of Canada compared to non-Indigenous Canadians, with Indigenous women experiencing the highest rates of sexual violence. While the above-mentioned groups are more likely to be subjected to sexual violence, they tend to encounter more barriers when accessing resources and often receive very little public attention or policy interventions. In Canada there are more than 1000 murdered and missing women, with very little in terms of meaningful policies and programs to address the ongoing gendered violence.

\section{Post-Secondary Campuses}

Presently, with $1 / 3$ of first year students subjected to sexual assault, sexual violence on university and college campuses is an ongoing and important issue for post-secondary institutions (Senn et al., 2014). In North America, 23.1\% of female-identified undergraduate students and $21 \%$ of transgender or gender nonconforming students have experienced an incident of sexual violence on campus, which indicates that first-year students, transgender or gender nonconforming students, and students who identify as women ${ }^{3}$ appear to be at a higher risk of being subjected to sexual violence (Chiara \& Lavina, 2014; Garcia et al., 2011; RAINN, 2016; Senn et al., 2014; Quinlan, Clarke, \& Miller, 2016; Tamburri \& Samson, 2014).

In the United States, Title IX of the Education Amendments of 1972 requires universities and colleges to provide women with appropriate resources to address gender inequality (Hayes-Smith \& Hayes-Smith, 2009). Amendments to Title IX, made in 1992 and 1998, mandates federally funded four-year universities and colleges to have sexual violence policies and prevention programming (Hayes-Smith \& Levett, 2010). US legislation includes the Student-Right-to-Know and Campus Security Act of 1990. Collectively, these legislations require post-secondary institutions to disclose campus crime statistics and provide prevention and security policies (Yung, 2015).

Canada does not have similar legislation and as such, Canadian post-secondary institutions are not required to disclose campus crime statistics or to provide policies pertaining to sexual violence (Quinlan et al., 2016). There are concerns that Canadian post-secondary institutions are currently failing to keep students informed about potential threats on campus (Desai, 2016). For instance, students at the University of Toronto pointed out the alarming discrepancy in the school's response to plagiarism (which resulted in 257 expulsions) and sexual assault (with zero expulsions) (Weikle, 2016). These statistics indicate that $\mathrm{U}$ of $\mathrm{T}$ presently has more procedures to deal with plagiarism than sexual violence, which is indicative of institutional priorities.

Post-secondary institutions tend to deal with sexual violence by offering preventive education and workshops, which typically focus on victims and/or potential victims and their responsibility to manage risks of sexual violence. Some preventative workshops perpetuate myths that violence can be prevented by due diligence and responsible behavior (Garcia et al., 2011; Orchowski, Meyer \& Gidycz, 2009). This facilitates a victim-blaming discourse, whereby responsibility falls to the victims to make responsible choices and sexual violence is deemed to be the result of victims' "wrong" decisions.

In addition, some post-secondary institutions' protocols and policies tend to rely upon 
narrow ideas about sexual violence (Gray \& Pin, 2016). For instance, despite the fact that $80 \%$ of sexual assault is committed by someone known to the victim university services, response protocols tend to understand sexual assaults as violence committed by strangers (McMahon, 2008). It is precisely such (mis)understandings that led the University of British Columbia to respond to six sexual assaults on campus in 2013 by announcing improved lighting and increased security patrols (Tamburri \& Samson, 2014). As seen above, many schools' prevention tactics are primarily concerned with security, and policing low traffic and/or poor lighting areas. Such practices reinforce the false notions of sexual assault as an act of violence committed by strangers in dark in unpoliced areas (Gray \& Pin, 2016).

\section{Policies}

While sexual assault is a gendered issue, the language used within policies tends to be un-gendered (Iverson, 2015). To illustrate, within Canada, 99\% of sexual assaults of women are perpetrated by men, while $87 \%$ of sexual assault against both men and women are perpetrated by men (Benoit et al., 2015). Canadian data also shows an increase in incidents of sexual violence against transgender individuals (Gunraj et al., 2014). However, sexual violence policies are not aligned with this reality. Policies tend to have a cursory understanding of the intersectional nature of violence (Gunraj et al., 2014; Iverson, 2017). An intersectional understanding of violence would be reflected in policies that consider the disproportionately higher rates of sexual violence being committed against Indigenous women, women with disabilities, 2SLGBTQIA, and women of color (Mahony, Jacob \& Hobson, 2017; Shankar, 2017). As pointed out by Iverson (2015), the creation of sexual violence policies is a political act embedded with bias. In order to avoid the simplistic language and understanding of policies that serve to perpetuate exclusionary practices and propagate marginalization of vulnerable populations, an intersectional feminist policy analysis is required. A greater understanding of how violence affects individuals is needed because the current efforts that have been put forth by schools has not lessened the incidence of sexual violence on campus (Iverson, 2015).

Currently, sexual violence is grossly underreported. Low reporting rates means that victims are not getting help and the perpetrators are not being punished (Orchowski, Meyer \& Gidycz, 2009). People may be discouraged from reporting due to the stigma surrounding sexual violence, fear of negative repercussions (such as blame or disbelief), and loss of confidentiality and privacy (Orchowski, Meyer \& Gidycz, 2009; Walsh et al., 2010). Students' knowledge of and access to resources increases their likelihood of reporting sexual violence (Garcia et al., 2011). Institutions can aid in students' overall recovery and health by providing prompt, confidential and considerate responses to disclosures and through provision of additional resources and assistance (Orchowski, Meyer \& Gidycz, 2009). Without such support, students may leave school, have long-term health concerns, and find their educational and life goals impeded (Garcia et al., 2011; Orchowski, Meyer \& Gidycz, 2009).

Policies, along with other meaningful resources and programs, are a useful starting point in addressing sexual violence on campus. A stand-alone policy on sexual violence demonstrates an institution's commitment to dealing with sexual violence and provides a clear delegation of the process and procedures in effect for dealing with sexual violence 
(Gonzales, Schofield \& Schmitt, 2005). Research indicates that reporting is aided by policies that contain clearly stated response protocols, services for victims, and permit anonymous and confidential reporting (Gonzales et al., 2005). It is imperative that post-secondary institutions provide stand-alone policies that are easily accessible and available to all students. These policies need to be student-centered and include regular monitoring and assessment of their effectiveness (Gunraj et al., 2014).

Some provinces have introduced legislation, such as Ontario's Bill 132: The Sexual Violence and Harassment Action Plan Act, which requires all post-secondary institutions in that province (as of January 2017) to have a sexual assault policy in place. Bill 132 mandates a school policy review every three years, and the collection of data on sexual violence (Legislative Assembly of Ontario, 2016). British Columbia's Bill 23: Sexual Violence and Misconduct Policy Act requires all post-secondary institutions to have a sexual assault policy in place within one year of the bill passing, and all policies to be reviewed every three years (Legislative Assembly of British Columbia, 2016). Manitoba recently passed Bill 3: The Post-Secondary Sexual Violence and Sexual Harassment Policies Act, which requires all post-secondary schools in the province to have a sexual assault policy in place and for it to be developed with student input (Legislative Assembly of Manitoba, 2016). Overall, these bills pertain to all publicly funded institutions, include definitions of sexual violence (except Manitoba) and delineate how each institution will respond to and report sexual violence. British Columbia and Ontario's bills require data on sexual violence to be collected by the post-secondary institution and distributed to the board of governors and provincial ministry office for review. It also contains measures to evaluate the effectiveness of universities' sexual violence processes. As stated earlier, Manitoba does not have similar requirements in the current bill. Unfortunately, only British Columbia requires dissemination of the sexual violence data to students, and the general public. Each of these three bills ignores intersectionality of violence in its policy. In other words, no reference is made to the reality that certain students are more likely to experience violence and thus, university campuses should have services equipped to assist students with intersectional identities and lived experiences. As discussed earlier, marginalized, Indigenous, disabled, and/or 2SLGBTQIA people are more likely to be subjected to sexual violence. While there is room for improvement within these bills, they are a promising start.

Alberta has not followed suit with similar legislation. Nonetheless, in September of 2016, the Minister of Advanced Education stated that all 26 publicly funded colleges and universities are expected to have sexual assault policies in place (Derworiz, 2016). The Ministry of Advanced Education has called for standardized stand-alone sexual violence policies that address training, prevention, complaint procedures, and response protocols (Derworiz, 2016). According to the Minister at the time, Marlin Schmidt, as of September 2016, 22 of the 26 institutions were in the process of developing their policies; the other 4 already had policies in place (Derworiz, 2016).

In light of former Minister Schmidt's statement and because Alberta currently does not have legislation requiring institutions to have a stand-alone sexual violence policy, it is important to examine the readiness of various institutions to meet their students' needs. In this study, we examined Alberta's post-secondary institutions to determine:1) the availability of a sexual violence policy, and 2) students' access to resources on sexual violence. We utilized publicly available data to ascertain whether each Albertan post-sec- 
ondary institution has a sexual violence policy which is readily and easily accessible to the student, and the ease with which students can access university resources and support services for sexual violence. This study demonstrates that, despite the Minister of Advanced Education's assurances, at the time of this study most institutions did not have a readily accessible policy on sexual violence. We are hopeful that this study will encourage post-secondary institutions to: 1 ) institute measures to increase student accessibility to policies, 2) create policies where one is currently missing, and 3) increase both availability of and student accessibility to support services and resources - both on and off campus.

\section{Methodology}

\section{Data Collection}

In Alberta, there are 21 publicly funded institutions, 5 privately funded and 5 First Nations colleges for a total of 31 post-secondary institutions across Alberta (see Table 1). These institutions offer a wide range of programming from arts workshops and internships at Banff Centre to places that focus on trades, such as Keyano College. The mandates of each of these institutions are quite diverse, along with size and composition of the student populations. Thus, the policies themselves would need to be designed to reflect the particular needs of each student population. Accordingly, in this study, we did not compare the institutions' policies to each other. Rather, we wanted to examine the ease with which a potential student could find their institution's sexual violence policy, the process for reporting sexual violence, and resources and support services available for students dealing with sexual violence. Thus, we relied upon the post-secondary institutions' websites and publicly available information to inform our analysis. The data for this research was collected in May and June of 2017.

Magnussen collected publicly available information on university websites and, where information was unclear, she followed up with phone calls to each institution requesting information on the institutional process for reporting sexual violence on campus and the services available on campus for their students. The website analysis included a careful review of university student resources and campus support programs. She examined each institutions' website for links to services, located on and off campus. She also searched for each institution's policy on sexual violence by reviewing all policy documents available online. Finally, Magnussen searched for relevant policies and programs by entering key search terms on each institution's website (such as sexual violence, rape, sexual assault, sexual harassment, stalking, date rape). This last step was intended to replicate the key terms a student in crisis may enter in their search for relevant policies and support services. As stated earlier, when information on a website was unclear or unavailable, Magnussen called each institution and asked for a copy of their policy/policies pertaining to sexual violence and their process for aiding a student who wanted to either report sexual violence and/or seek assistance for sexual violence.

Since we relied upon publicly available data, as per the guidelines of Mount Royal University's Human Research and Ethics Board, an ethics application was not required. This study contains review of 21 publicly funded, 5 independent and 5 First Nations postsecondary institutions. 


\section{Analysis}

Magnussen and Shankar reviewed and analyzed the collected data together. Both researchers, a tenured faculty member and a senior undergraduate student, are well acquainted with the structure and functioning of post-secondary institutions. Our in-depth knowledge of sexual violence, familiarity with post-secondary students' experiences of marginalization and violence, and our own gendered and racialized experiences of being in post-secondary institutions led us to research this topic.

Our analysis was informed by intersectional feminist paradigm, which allows us to study all forms of intersecting identities and their related systems of oppression (Crenshaw, 1993; Hesse-Biber, 2014). Crenshaw (1991) originally coined the term intersectionality to highlight the lack of legal protection for Black women who simultaneously encounter racism and sexism in the workplace. In response to the oversimplification of intersectionality theory, Bilge (2013) and Tomlinson (2013) urge intersectional feminist researchers to have in-depth understanding of and commitment to social justice, and racial equality.

As intersectional feminist researchers, our analysis is grounded in the larger feminist critique of post-secondary institutions as exclusionary spaces (Ahmed, 2012; Puwar, 2004). Accordingly, we paid particular attention to how race, gender, class, sexual orientation and ability are considered or neglected within sexual assault services for students in higher education institutions. By analyzing this data through an intersectional feminist lens, we acknowledge that the experiences of people who belong to various and compounding social categories cannot be looked at singularly (Bilge, 2013; Crenshaw, 1993; Tomlinson, 2013). In other words, there needs to be a clear recognition that a student dealing with sexual violence may require services and policies that understand and meaningfully address transphobia, homophobia, ableism, racism, colonialism, and sexism, because violence is embedded in each of these ideologies and they are all connected in the lived experiences of individuals. Accordingly, we looked at policies and resources in terms of their ability and readiness to assist students with intersectional identities (Yuval-Davis, 2015). For example, racialized, Indigenous, and 2SLGBTQIA students are more likely to be subjected to sexual violence (Gunraj et al., 2014; Iverson, 2017). Thus, we reviewed institutions' websites and recommended services for victims of sexual violence for overt understanding and recognition that marginalized people with intersectional identities are more likely to subjected to sexual violence and may experience more obstacles in accessing and utilizing services and programs for victims of sexual violence on campus.

\section{Findings and Discussion}

Our findings indicate that most of Alberta's universities and colleges currently lack a clearly identifiable stand-alone sexual assault policy, and knowledge on how to respond to inquiries regarding sexual violence and that in absence of clearly designated protocols, the caller gets directed to either security and/or an outside community agency. Accordingly, we will discuss these findings and their implications below. 
Table 1. Overview of Sexual Assault Policies and Resources at Alberta's Post-secondary Institutions

\begin{tabular}{|c|c|c|c|}
\hline & Institution & $\begin{array}{l}\text { Stand-alone } \\
\text { Policy }\end{array}$ & $\begin{array}{l}\text { Dedicated Sexual } \\
\text { Violence Re- } \\
\text { source Website }\end{array}$ \\
\hline \multirow{21}{*}{$\begin{array}{l}\text { Publicly Funded } \\
\text { Institutions }\end{array}$} & Alberta College of Art and Design & No & No \\
\hline & Athabasca University & No & No \\
\hline & The Banff Centre & No & No \\
\hline & Bow Valley College & Yes & Yes \\
\hline & Grand Prairie Regional College & No & No \\
\hline & Grant MacEwan University & Yes & Yes \\
\hline & Keyano College & No & No \\
\hline & Lakeland College & No & No \\
\hline & Lethbridge College & Yes & No \\
\hline & Medicine Hat College & Yes & No \\
\hline & Mount Royal University & Yes & Yes \\
\hline & $\begin{array}{l}\text { Northern Alberta Institute of Tech- } \\
\text { nology }\end{array}$ & Yes & Yes \\
\hline & NorQuest College & Yes & No \\
\hline & Northern Lakes College & Yes & Yes \\
\hline & Olds College & Yes & No \\
\hline & Portage College & No & No \\
\hline & Red Deer College & No & Yes \\
\hline & $\begin{array}{l}\text { Southern Alberta Institute of Tech- } \\
\text { nology }\end{array}$ & Yes & Yes \\
\hline & University of Alberta & No & Yes \\
\hline & University of Calgary & Yes & Yes \\
\hline & University of Lethbridge & Yes & Yes \\
\hline \multirow{5}{*}{$\begin{array}{l}\text { Independent } \\
\text { Institutions }\end{array}$} & Ambrose University & Yes & Yes \\
\hline & Burman University & No & No \\
\hline & Concordia University of Edmonton & Yes & Yes \\
\hline & King's University & Yes & Yes \\
\hline & St. Mary's University & No & No \\
\hline \multirow{5}{*}{$\begin{array}{l}\text { First Nations Col- } \\
\text { leges }\end{array}$} & Blue Quills University & No & No \\
\hline & Maskwacis Cultural College & No & No \\
\hline & Old Sun Community College & No & No \\
\hline & Red Crow Community College & No & No \\
\hline & Yellowhead Tribal College & No & No \\
\hline
\end{tabular}


Sexual assault policy. Stand-alone sexual violence policies are crucial for creating uniformity among procedures and making staff and students aware of the policies that govern their institution. These policies designate consequences for perpetrators, inform victims of their rights, and ensure access to adequate services. A lack of information on organizational understanding and response to sexual violence makes post-secondary campuses a precarious environment for students affected by sexual violence (Armstrong et al., 2006; Beres, Crow \& Gotell, 2009).

As indicated in Table 1, 14 out of 31 post-secondary institutions had clearly designated stand-alone sexual violence policies publicly available on their websites. Another six institutions had guidelines or protocols pertaining to sexual violence as part of a larger policy on student conduct, discrimination and harassment or students' rights and responsibilities. Two of the institutions were currently in the process of developing policies while the rest (9 out of 31) either did not have a sexual violence policy or it was inaccessible. It is possible these nine institutions have policies in place but they were not listed on their website. However, the lack of online accessibility to such policy hinders students' ability to quickly access information. As stated earlier, students tend to rely on the web for information and resources on sexual violence (Garcia et al, 2012; Krivoshey et al, 2013). Thus, by listing their policies and support services online, institutions can quickly provide students' information on how their institution deals with sexual violence and what they can expect to happen once they report/disclose incidence of sexual violence (Krivoshey et al., 2013).

Currently, approximately $65 \%$ of Alberta's post-secondary institutions have some form of a policy on sexual violence (either standalone or part of a larger policy). This leaves the remaining 35\% of Alberta post-secondary schools (as of June, 2017) lacking in processes and techniques necessary for properly handling the issue of sexual violence on campus. As indicated in Table 2, 11 of the 21 publicly funded institutions (52\%); 3 of the 5 independent institutions (60\%) and none of the First Nations Colleges (o\%) have a publicly available sexual violence policy (as standalone policies or as part of another policy). As mentioned earlier, due to ongoing colonialism, violence against Indigenous Canadian women is three times higher than against non-Indigenous Canadian women (Brennan, 2011). Thus, it is concerning that Indigenous students at First Nations institutions do not have clearly accessible sexual violence policies and services. It is important to contextualize these findings: the lack of accessible policy could be from the precarious funding structure of these institutions and not due to a lack of interest or demand. For instance, in 2016, the Parliamentary Budget Office reported approximately $\$ 665$ million gap in educational funding for First Nations and non-First Nations (Morin, 2017).

It is crucial to have a stand-alone policy that is publicly available to all members of the campus, as a stand-alone policy that can be easily reached in times of crisis spells out institutional procedures, rights of victims, and services available. Presently, as discussed above, only 14 of Alberta's post-secondary institutions have a stand-alone policy, which demonstrates a prevailing need for stand-alone sexual violence policies on Albertan campuses.

A stand-alone policy on sexual violence should include, 1) an extensive list of forms of sexual violence, with descriptions to help people identify their experiences, 2) an outline of the reporting process, including contact information, 3) emphasis that the victim's identity will remain anonymous, including anonymous reporting options, 4) third-party reporting options and 5) 24-hour accessibility to reporting (Krivoshey et al., 2013). It is also impor- 
tant that schools publish these policies online so they can be accessed anonymously and easily (Krivoshey et al., 2013). Governmental legislation requiring post-secondary schools in Alberta to have stand-alone sexual violence policies, with the features mentioned above, will assist students in need, encouraging reporting, and demonstrating the need for resources for university students dealing with this issue (Krivoshey et al., 2013).

Clear referral to resources. In addition to a stand-alone policy regarding sexual violence, all post-secondary institutions should have an easily accessible online link to resources for people dealing with sexual violence (Hayes-Smith \& Hayes-Smith, 2009; Krivoshey et al., 2013). Research indicates that university students heavily rely upon the Internet to find information on topics related to sexual health (Escoffery et al., 2005; Hayes-Smith \& Hayes-Smith, 2009). A dedicated website for these resources allows students in crisis to quickly access available on- and off-campus services at any time of the day or night (Krivoshey et al., 2013). The confidentiality and anonymity of the internet can also encourage reporting of incidents of sexual violence as victims can access information without having to disclose their experience to a stranger or fear judgement from people in authority (Krivoshey et al., 2013; Orchowski et al., 2009). The stigma surrounding sexual violence makes people hesitant to disclose and thus online access to information increases the likelihood of victims accessing resources (Hayes-Smith \& Hayes-Smith, 2009; Walsh et al., 2010). Along with having programs to help those dealing with sexual violence, it is also crucial that these programs be clearly labelled, easy to find, and readily accessible online to students in distress.

Table 2. Accessibility and Availability of Support Services/Resources for Sexual Violence

\begin{tabular}{|l|l|l|l|l|}
\hline $\begin{array}{l}\text { Post-secondary Institu- } \\
\text { tions }\end{array}$ & $\begin{array}{l}\text { Number } \\
\text { of PSE in } \\
\text { Alberta }\end{array}$ & $\begin{array}{l}\text { Has dedicated on } \\
\text { campus services } \\
\text { for sexual violence }\end{array}$ & $\begin{array}{l}\text { Contains on } \\
\text { campus non- } \\
\text { specialized } \\
\text { services }\end{array}$ & $\begin{array}{l}\text { Refers students } \\
\text { to community } \\
\text { services }\end{array}$ \\
\hline Publicly Funded Institutions & 21 & 8 & 11 & 11 \\
\hline Independent Institutions & 5 & 2 & 2 & 2 \\
\hline First Nations Colleges & 5 & 0 & 0 & 0 \\
\hline Total & 31 & 10 & 13 & 13 \\
\hline $\begin{array}{l}\text { *non-specialized services refer to counselling, campus security services, chaplain/ } \\
\text { pastoral services, and campus health centre. }\end{array}$ & \\
\hline
\end{tabular}

As indicated above (see Table 2), among the 31 post-secondary institutions in Alberta, only 14 (45\%) had easily accessible online links/information on resources for sexual violence. This does not mean that the rest of the institutions do not have resources/programs that aid students for various issues, including sexual violence. Some universities (such as, Concordia University of Edmonton) have a webpage with information on how and to whom students can report sexual violence and a write-up on scenarios where someone is unable to provide consent (such as when intoxicated, asleep, and under duress). However, such websites do not indicate resources for students who require services but do not want to report violence. Others (such as Bow Valley College and Northern Lakes College) have protocols and policies available online but no link to specific resources because the website is currently unavailable. As our focus was on the online availability of resources 
that directly referenced sexual violence, we only counted those institutions that have clear online links to resources (either on- or off-campus) that students can access.

The lack of adequate policies and inaccessibility of resources tells students that their safety and well-being are not being prioritized. Furthermore, this gap in accessible information and services for students dealing with sexual violence can further exacerbate the consequences of such events. Students who experience sexual violence on campus may choose to leave school temporarily or permanently, as well as encounter feelings of depression, shame, and isolation (Garcia, et al., 2011). On the other hand, when victims of sexual violence are connected with support and professional resources it can reduce feelings of isolation, improve recovery, and lessen the risk of re-victimization (Orchowski, Meyer \& Gidycz, 2009; Walsh, et al., 2010).

On campus resources for sexual violence. As indicated in Table 2, only 10 (32\%) of the institutions listed their on-campus resources on sexual violence on their websites. Among these institutions, there appears to be a wide range in how services are administered. In some institutions, such as MacEwan University, students can access a sexual violence response team through a contact person at the university's security services. Other institutions, like Mount Royal University, have a dedicated sexual violence response and awareness coordinator. Within Alberta, only the University of Alberta has a clearly labelled on-campus centre dedicated to dealing with sexual violence. The presence of this dedicated centre on campus helps staff direct calls and inquiries, creating a streamlined process for accessing information. Some institutions provide sexual violence services that are housed under generic services that may not clearly indicate the availability of sexual violence support services to students. For instance, Ambrose University provides sexual violence resources through Ambrose Community Advocates and King's University provides similar services through its Harassment Committee. Overall, our findings indicate that most post-secondary institutions in Alberta either do not have dedicated centres/ offices or on-campus services for sexual violence and/or they are not well advertised on their institutional webpages. In either case, many post-secondary students in Alberta currently lack clear means of identifying and accessing sexual violence support services on their campuses.

For those institutions who did not list their resources and services online, phone calls inquiring about resources regarding sexual violence were met with uncertainty on where to direct our inquiries ( 4 times). There were also six incidences of being transferred to the wrong person who seemed similarly perplexed and uncertain as to why we had contacted them. In several instances, the inquiry was transferred from two to six times trying to find the best person to answer questions about sexual violence on campus. Nine of the institutions failed to return our calls for inquiry. While this data is not conducive for generalization, it speaks to the confusion a student seeking services may encounter. This drawn-out and frustrating process lessens the likelihood of an individual reporting sexual violence and makes it more difficult for them to learn about and access appropriate services. In addition, this confusion speaks to the need of every institution to have a clearly-designed and accessible web page with a complete list of on- and off-campus resources for sexual violence.

Referral to security and counselling. As indicated in Table 2, among universities that clearly list their support services (45\% of Alberta's post-secondary institutions) 
there is a heavy reliance upon generic services such as security and counselling to provide sexual violence support services. First, referral to counselling services (provided the institution employs counsellors who are trained to respond to sexual violence in a nonjudgmental, inclusive, non-heteronormative, and inclusive manner) is understandable. However, within our investigation, the main resource offered to students tended to be their on-campus security office. Moreover, once connected to security the same problems persisted whereby staff were often unsure of how to answer questions and there was no set procedure/protocol they could identify. Again, this is not meant as a generalization but rather a persistent obstacle we encountered in trying to access information on institutional programs and services.

Research indicates that students should have comprehensive access to a 24-hour resource that is not directly related to the campus security department (Krivoshey et al., 2013). Campus security can be one option for student reporting sexual violence but this should not be the primary option available for all victims. The likelihood of disclosure lessens if victims of sexual violence believe they may be required to press charges or file a formal complaint with the school (Ministry of the Status of Women, 2013). Victims of sexual violence often do not report the incident to authorities out of fear of having to retell details of the incident, and thus experiencing re-traumatization (Ministry of the Status of Women, 2013). Moreover, security staff are generally not adequately trained in proper sexual violence response methods and/or trauma counseling. Although some universities are taking measures to educate and provide additional training to their security team, even properly trained security officers may not be an ideal option for marginalized/ racialized students given the long history of racial profiling by on- and off-campus policing and security services (Goodey, 2006). A study by Nance (2017), found that racialized students are likely to have previously experienced extreme scrutiny, surveillance, and/ or violence by security staff. Additionally, schools with over 50\% students of color employ more security measures and provide harsher treatment than schools with a majority white population (Nance, 2017). Considering the increased incidences of surveillance and violence experienced by marginalized communities in Canada, the reliance upon security in post-secondary institutions as the first response needs to be carefully deliberated.

Reliance upon off campus resources. Community organizations trained in responding to sexual violence can be an asset to post-secondary institutions in assisting with training of staff and providing resources for victims. Accordingly, most of the publicly funded institutions examined (with exception of Red Deer College) had links to off campus and community-based resources. Collaborative relationships among institutions and community-based resources specializing in sexual violence can be extremely useful to students in need. Often (but not always) community organizations have specialized counsellors that are well trained in inclusive and intersectional understanding of sexual violence. There are two particular issues to consider in relation to this finding: first, why are these publicly available community resources not easily accessible (through links) on the website of every post-secondary institution? Second, the reliance and partnership with these organizations should not exempt institutions from developing and housing on campus resources/services for their students. Solely referring students to off campus services does not provide institutions with in depth knowledge of their students' needs. On-campus resources for sexual violence can increase feelings of safety for students and increase awareness of available resources (RAINN, 2016). Moreover, on-campus services 
such as peer counselling for sexual violence can facilitate in the creation of a community for survivors. When victims of sexual violence seek help from others it can reduce feelings of isolation and encourage connections with support and professional resources (Walsh et al., 2010). Finally, as pointed out by Krivoshey et al (2013) “... key college stakeholders, including college administrators, college mental health professionals and campus security, [need to] become more familiar with sexual assault on their campus" (p. 146) and this can be achieved with on campus services that will record prevalence rates, trends, and their ability to meet the needs of their students.

Limitations and further recommendations. Due to the specific time and location of this research, it cannot be generalized to other post-secondary institutions. In addition, by the time of publication, some of the post-secondary institutions will have addressed their lack of policy and accessibility to services. This study solely examined students' online accessibility of services and not the quality, comprehensiveness or effectiveness of the available policies and services (such as whether the policies and services are cultural sensitivity, accessible to students with disabilities, have comprehensive operating hours, and/or contain other barriers such as transportation requirement, fees, lengthy waiting list etc.). This study's limitations can be addressed through further research on other post-secondary institutions polices and resources on sexual violence. Specifically, future research on the effectiveness, accessibility, university members' awareness, perception, and utilization of sexual violence policies and services are needed, and the existing policies and services can better meet the needs of marginalized individuals/groups. A detailed examination of institutional policies and resources (including provinces with legislation referencing stand-alone policies) would provide a better understanding of how Canada's post-secondary institutions are dealing with sexual violence on campus and would highlight outstanding issues that require further attention.

\section{Conclusion}

As seen in this paper, contrary to the Minister of Advanced Education's assertions (Derworiz, 2016), there is limited availability and accessibility to post-secondary institutions' sexual violence policies. Moreover, there is some confusion on where to refer students in crisis and a lack of online access to both policies and resources on sexual violence. Unlike other provinces (such British Columbia, Manitoba and Ontario) where legislation will compel universities to institute adequate sexual violence policies and increase their students' access to resources, Alberta is currently relying upon the goodwill of its institutions. However, as indicated in this paper, as of June 2017, many Albertan universities currently do not have a stand-alone policy or easily accessible resources. This could be due to ongoing funding cuts made to post-secondary institutions in Alberta. Nonetheless, post-secondary institutions are still failing to meet the needs of their students, particularly vulnerable and marginalized students.

The current lack of cohesion within Canada (where provinces differ in their responses) in reference to policies and clear designation of protocols on sexual violence by university administrators and policy makers speaks to the inequalities present in the broader society (Armstrong et al., 2006; Gunraj et al., 2014). Social institutions and the documents that make up institutions, such as sexual violence policies, have the power to influence behavior. These policies (or the lack thereof) can either effectively address violence and 
support the victims or it can create conditions that normalize sexual violence. In order to be have more responsive resources, policies, and services for students, post-secondary institutions have to change, and their sexual violence policies and resources should demonstrate a commitment to an intersectional framework. This would require the inclusion of marginalized students, intersectional feminist scholars, and experts on sexual violence to be part of the planning phases of policy development. It is only through such practices that policies will better meet the needs of students dealing with sexual violence, who disproportionately tend to be young, racialized and identify as women.

\section{Notes}

1. Partnered with Columbia University.

2. Brandon University has confirmed the existence of the contract.

3. In this paper, we use the term "women" to refer to all persons who identify as women and/or female.

\section{References}

Ahmed, S. (2012). On being included: Racism and diversity in institutional life. Durham, NC: Duke University Press.

Altier, C. (2015, June 5). Student who carried mattress in rape protest unveils new project. TIME. Retrieved from http://time.com/3910621/emma-sulkowicz-mattresscolumbia-rape-video/

Aluwihare-Samaranayake, D. (2012). Ethics in qualitative research: A view of the participants' and researchers' world from a critical standpoint. International Journal of Qualitative Methods, 11(2), 64-81.

Armstrong, E. A., Hamilton, L., \& Sweeney, B. (2006). Sexual assault on campus: A multilevel, integrative approach to party rape. Social Problems, 53(4), 483-499.

Association Committee on Women in the Academic Profession, \& Subcommittee on Sexual Assault on Campus. (2012, November). Campus sexual assault: Suggested policies and procedures. Retrieved from https://www.aaup.org/file/Sexual_Assault_Policies.pdf

Benoit, C., Shumka, L., Phillips, R., Kennedy, M. C., \& Belle-Isla, L. (2015). Issue brief: Sexual violence against women in Canada. The Federal-Provincial-Territorial Senior Officials for the Status of Women, 1-55.

Beres, M. A., Crow, B., \& Gotell, L. (2009). The perils of institutionalization in neoliberal times: Results of a national survey of Canadian sexual assault and rape crises centers. Canadian Journal of Sociology, 34(1), 135-163.

Bilge, S. (2013). Intersectionality undone: Saving intersectionality from feminist intersectionality studies. Du Bois Review, 1O(2), 405-424.

Brennan, S. (2011). Violent victimization of aboriginal women in the canadian provinces, 2009. Juristat. Catalogue no. 85-002-X. Retrieved from http://www.statcan. gc.ca/pub/85-002-x/2011001/article/11439-eng.pdf 
Briscoe, J. (2017, January 29). What happened to Stanford rapist Brock Turner news \& updates. Gazette Review. Retrieved from http://gazettereview.com/2017/o1/ happened-stanford-rapist-brock-turner-news-updates/

Browne, R. (2014, October 30). Why don't Canadian universities want to talk about sexual assault? Macleans. Retrieved from http://www.macleans.ca/education/ unirankings/why-dont-canadian-universities-want-to-talk-about-sexual-assault/

Conroy, S., \& Cotter, A. (2017). Self-reported sexual assault in canada, 2014. Juristat. Catalogue no. 85-002-X, 1-34. Retrieved from http://www.statcan.gc.ca/pub/85002-x/2017001/article/14842-eng.pdf

Coorsh, K. (2016, April 5). Brandon U president says "behavioural contract" for sex assault victims was a mistake. CTV News. Retrieved from http://www.ctvnews.ca/ canada/brandon-u-president-says-behavioural-contract-for-sex-assault-victims-was-amistake-1.2846190

Crenshaw, K. (1993). Mapping the margins: Intersectionality, identity politics, and violence against women of color. Stanford Law Review, 43, 1241-1299.

Day, K. (1994). Conceptualizing women's fear of sexual assault on campus: A reviews of causes and recommendations for change. Environment and Behavior, 26(6), 742-765.

Derworiz, C. (2016, September 8). Province expects all publicly funded Alberta universities and colleges to adopt sexual assault policies. Calgary Herald. Retrieved from http://calgaryherald.com/news/local-news/campus-safety--

Desai, S. (2016, August 9). How Canadian universities are failing sexual assault survivors. Now Toronto. Retrieved from https://nowtoronto.com/news/how-canadianuniversities-are-failing-sexual-assault-survivors/

Enos, E. (2017, January 16). Sexual violence widespread at Quebec universities, study finds. $C B C$ News. Retrieved from http://www.cbc.ca/news/canada/montreal/sexualassault-campus-quebec-victimization-1.3937527

Escoffery, C., Miner, K., Adame, D. D., Butler, S., McCormick, L., \& Mendell, E. (n.d.). Internet use for health information among college students. Journal of American College Health, 53(4), 183-189.

Gagnon, J., \& Grinberg, E. (2016, September 4). Mad about Brock Turner's sentence? It's not uncommon. CNN. Retrieved from http://www.cnn.com/2016/09/02/us/brockturner-college-athletes-sentence/

Garcia, C. M., Lechner, K. E., Frerich, E. A., Lust, K. A., \& Eisenberg, M. E. (2012). Preventing sexual violence instead of just responding to it: Students' perceptions of sexual violence resources on campus. Journal of Forensic Nursing, 8, 61-71.

Gonzales, A. R., Schofield, R. B., \& Schmitt, G. R. (2005). Sexual assault on campus: What colleges and universities are doing about it. National Institute of Justice: U.S. Department of Justice Office of Justice Programs. Retrieved from http://www.ncjrs.gov/ pdffiles1/nij/205521.pdf

Goodey, J. (2006). Ethnic profiling, criminal (in)justice and minority populations. Critical Criminology, 14(3), 207-212. 
Gray, M., \& Pin, L. (2016). Invisible supports: Examining undergraduate students' knowledge of sexual assault resources at York University. Retrieved from http:// www.womanact.ca/uploads/1/8/6/8/18687524/2016-final-gray-and-pin-invisiblesupports__1_.pdf

Gunraj, A., Wandio, C., Abdullah, S., Komiotis, W., Marshall, P., Mustachi, J., Rahim, C., \& Witelson, T. (2014). Sexual assault policies on campus: A discussion paper. METRAC Action on Violence. Retrieved from http://www.metrac.org/wp-content/ uploads/2014/11/final.formatted.campus.discussion.paper_.26sept14.pdf

Haraway, D. (1988). Situated knowledges: The science question in feminism and the privileges of partial perspective. Feminist Studies. 14, 575-599.

Hayes-Smith, R., \& Hayes-Smith, J. (2009). A website content analysis of women's resources and sexual assault literature on college campuses. Critical Criminology, 17(2), 109-123.

Hayes-Smith, R., \& Levett, L. (2010). Student perceptions of sexual assault resources and prevalence of rape myth attitudes. Feminist Criminology, 5(4), 335-354.

Hesse-Biber, S. (2014). A re-invitation to feminist research. In S. Hesse-Biber (Ed). Feminist Research Practice: A Primer. (pp. 1-13). Thousand Oaks, CA: SAGE Publications Inc.

Iverson, S. V. (2015). A policy discourse analysis of sexual assault policies in higher education. In S.C. Wooten \& W. Mitchell (Eds.). The Crisis of Campus Sexual Violence (pp. 15-32). New York, NY, US: Routledge/Taylor \& Francis Group.

Iverson, S.V. (2017). Mapping identities: An intersectional analysis of sexual violence policies. In J. Harris, \& C. Linder (Eds.), Intersections of identity and sexual violence on campus: Centering minoritized students' experiences (pp. 214-232). Sterling, VA: Stylus.

Krivoshey, M. S., Adkins, R., Hayes, R., Nemeth, J. M., \& Klein, E. G. (2013). Sexual assault reporting procedures at Ohio colleges. Journal of American College Health, 61(3), 142-147.

Laychuk, R. (2016, April 5). Brandon University sexual assault victims forced to sign contract that keeps them silent. CBC News. Retrieved from http://www.cbc.ca/news/ canada/manitoba/brandon-university-behavioural-contract-1.3520568

Legislative Assembly of British Columbia. (2016). Sexual violence and misconduct policy act, Bill 23. 40th Parliament. Retrieved from https://www.leg.bc.ca/parliamentarybusiness/legislation-debates-proceedings/40th-parliament/5th-session/bills/firstreading/gov23-1

Legislative Assembly of Manitoba. (2016). The post-secondary sexual violence and sexual harassment policies act, Bill 3. 40th Parliament. Retrieved from http://web2.gov. mb.ca/bills/40-5/boo3e.php

Legislative Assembly of Ontario. (2016). Sexual violence and harassment action plan act (supporting survivors and challenging sexual violence and harassment), Bill 132. Retrieved from http://www.ontla.on.ca/web/bills/bills_detail.do?locale=en\&BillID=3535

Mahony, T. H., Jacob, J., \& Hobson, H. (2017). Women and criminal justice system. 
[Catalogue no, 89-503-X]. Retrieved from https://www150.statcan.gc.ca/n1/pub/89503-x/2015001/article/14785-eng.pdf

McMahon, P. P. (2008). Sexual violence on the college campus: A template for compliance with federal policy. Journal of American College Health, 57(3), 361-364.

Ministry of the Status of Women. (2013, January). Developing a response to sexual violence: A resource guide for Ontario's colleges and universities. Retrieved from http:// www.citizenship.gov.on.ca/owd/english/ending-violence/campus_guide.shtml\#toc3avii

Morin, B (2017, August 31). First Nations students face continued funding shortfalls, advocates say. Retrieved from http://www.cbc.ca/news/indigenous/first-nationsstudents-face-continued-funding-shortfalls-1.4267540

Nance, J. (2017). Student surveillance, racial inequalities, and implicit racial bias. Emery Law Journal, 66(4), 765-837.

Orchowski, L. M., Meyer, D. H., \& Gidycz, C. A. (2009). College women's likelihood to report unwanted sexual experiences to campus agencies: Trends and correlates. Journal of Aggression, Maltreatment \& Trauma, 18(8), 839-858.

Pike, H. (2018, January 11). University of Calgary find they have 'no grounds' to expel convicted sex offender. Metro News. Retrieved from http://www.metronews.ca/ news/calgary/2018/o1/11/university-of-calgary-find-they-have-no-grounds-to-expelconvicted-sex-offender.html

Puwar, N. (2004). Space invaders: Race, gender and bodies out of place. New York, NY. Berg.

Quinlan, E., Clarke, A., \& Miller, N. (2016). Enhancing care and advocacy for sexual assault survivors on Canadian campuses. Canadian Journal of Higher Education, 46(2), 40-54.

RAINN. (2016). Campus sexual violence: Statistics. Retrieved from https://www. rainn.org/statistics/campus-sexual-violence

Sabina, C. \& Ho, L.Y. (2014). Campus and college victim responses to sexual assault and dating violence: disclosure, service utilization, and service provision. Trauma, Violence, \& Abuse, 15(3), 201-226.

Schonfeld, Z. (2014, April 24). Columbia University hit with federal complaint for mishandling sexual assault cases. Newsweek. Retrieved from http://www.newsweek.com/ columbia-university-hit-federal-complaint-mishandling-sexual-assault-cases-248613

Senn, C. Y., Eliasziw, M., Barata, P. C., Thurston, W. E., Newby-Clark, I. R., Radtke, H. L., ... SARE Study Team. (2014). Sexual violence in the lives of first-year university women in Canada: no improvements in the 21st century. BMC Women's Health, 13(135), 1-8.

Shankar, I. (2017). \#Morethanhashtags: Universities should take concrete actions to end campus sexual violence. Insider Higher Education. July 28, 2017, https://www. insidehighered.com/advice/2017/07/28/universities-should-take-concrete-actionsstop-sexual-assault-essay 
Shingler, B. (2016, December 1). McGill University aims for balanced approach with new sexual assault policy. CBC News. Retrieved from http://www.cbc.ca/news/canada/ montreal/mcgill-sexual-assault-policy-1.3872932

Tamburri, R., \& Samson, N. (2014, October 20). Ending sexual violence on campus. University Affairs. Retrieved from http://www.universityaffairs.ca/features/featurearticle/ending-sexual-violence-campus/

Tomlinson, B. (2013). Colonizing intersectionality: replicating racial hierarchy in feminist academic arguments. Social Identities, 19(2), 254-272.

Walsh, W. A., Banyard, V. L., Moynihan, M. M., Ward, S., \& Cohn, E. S. (2010). Disclosure and service use on a college campus after an unwanted sexual experience. Journal of Trauma \& Dissociation, 11(2), 134-151.

Weikle, B. (2016, September 13). Universities face increasing pressure to address campus sexual assault. CBC News. Retrieved from http://www.cbc.ca/news/canada/ campus-sexual-assault-1.3750355

Weinberg, M. (2002). Biting the hand that feeds you, and other feminist dilemmas in fieldwork. In W. C. van den Hoonaard (Ed). Walking the Tightrope: Ethical Issues for Qualitative Researchers. (pp. 79-94). Toronto, ON: University of Toronto Press.

Yung, C. R. (2015). Concealing campus sexual assault: an empirical examination. American Psychological Association, 21(1), 1-9.

Yuval-Davis, N. (2015). Situated intersectionality and social inequality. Raisons Politiques, 58(2), 91-100.

\section{Contact Information}

Irene Shankar, Associate Professor

Department of Sociology and Anthropology

Mount Royal University

ishankar@mtroyal.ca

Jacey Magnussen is completing her Master of Arts degree in the discipline of Sociology at the University of Calgary. Her master's thesis will examine the historical exclusion of women in the Canadian medical field, specifically Indigenous women identified healers. Her research focuses on intersectionality of exclusions, stemming from her work as a front-line worker assisting people dealing with homelessness and poverty.

Irene Shankar is an Associate Professor of Sociology at Mount Royal University. Dr. Shankar's research and teaching areas are situated within Intersectional Feminist Theories, Critical Race Theory, Qualitative Methodology, and the Sociology of Health and Illness. Her current projects examine the racialized and gendered constructions of individualized risk and responsibility within public health messages, and sexual violence policies and programs on university campuses. 